\title{
Government Low-Carbon Policies Optimization for Smart Transportation Enterprises
}

\author{
Kai Gao $\mathbb{D}^{1,2}$ Xin Guo $\mathbb{D}^{1},{ }^{1}$ Tingting Liu $\mathbb{D}^{3},{ }^{3}$ and Rui Han $\mathbb{D}^{1,4}$ \\ ${ }^{1}$ School of Management, Shanghai University, Shanghai 200444, China \\ ${ }^{2}$ School of Management, Shanghai University of Engineering Science, Shanghai 201620, China \\ ${ }^{3}$ School of International Trade and Economics, Shanghai Lixin University of Accounting and Finance, Shanghai 200120, China \\ ${ }^{4}$ School of Management, University of Sheffield, Conduit Road, Sheffield S101FL, UK \\ Correspondence should be addressed to Rui Han; hanrui97china@gmail.com
}

Received 9 November 2021; Accepted 28 December 2021; Published 31 January 2022

Academic Editor: Tingsong Wang

Copyright (c) 2022 Kai Gao et al. This is an open access article distributed under the Creative Commons Attribution License, which permits unrestricted use, distribution, and reproduction in any medium, provided the original work is properly cited.

\begin{abstract}
As an important part of energy saving and carbon reduction, the low-carbon development of the transportation industry is imperative. It is the responsibility of smart transportation enterprises to closely combine their own digital technology with the governments' policies to achieve green innovation. In this study, we conducted an evolutionary game model of the interaction between the governments and smart transportation enterprises, which depended on innovation subsidies and punitive taxes. Besides, we derived the evolutionarily stable strategy of the governments and enterprises and used a simulation to analyze the impact of various policy tools on green innovation strategy. The results showed that the behavior of the governments relies on the benefits of supervision and the costs of supporting green technology innovation. The enterprises' behavior depends on the benefits of green innovation and the loss of no green innovation. Moreover, different policy tools provided by the governments can accelerate the implementation of enterprises' green innovation.
\end{abstract}

\section{Introduction}

Greenhouse gas emissions' reduction has become a global consensus. The Paris Agreement has planned for the post2020 global response to climate change, proposing to limit the rise in global average temperature to $2^{\circ} \mathrm{C}$ above preindustrial levels. To achieve this, countries around the world must work together to promote carbon neutrality. For the whole world, China is the largest carbon emitter, accounting for $26.7 \%$ of the world's emissions in 2019, according to the United Nations Environment Programme (UNEP). With the deepening of China's urbanization and industrialization, it brings not only rapid economic growth but also brings severe problems. In the past three decades, China's greenhouse gas emissions have more than tripled. In 2020, China set a goal of achieving a carbon peak by 2020 and carbon neutralization by 2060 . To achieve this, many countries take many measures to reduce carbon emissions and develop low-carbon economies. In the way of conserving energy and reducing emissions, green innovation is considered to be effective [1-3].

Green technology innovation is an important element of traditional technology innovation. Different from traditional technological innovation, green innovation has double externalities. Firstly, pollution emission brings negative externalities to society and the environment. If the pollution emission of enterprises lacks policy constraints, the emission expenditure cost of enterprises is less than the social cost, which leads to excessive emission. Moreover, enterprises lack the incentive to implement green innovation. Secondly, owing to the positive externality of knowledge and technology spillover, green innovation enterprises bear all the innovation costs. If there is no policy intervention, there will be a lack of innovation power. Environmental policies help to encourage enterprises to introduce green product innovation and clean process innovation [4-6].

Transportation industry consumes a lot of energy, especially fossil fuels with high carbon emissions [7]. In 2013, 
the report released by WWF indicated that the average carbon emission intensity of the transportation industry was about 119 times that of the financial industry. Carbon emissions from China's transportation industry have continued to grow in recent years. We show the relevant data of carbon emissions in Figure 1. Faced with worsening climate and environment, many governments advocate low-carbon travel and focus on the construction of green transportation [8]. For example, the Chinese government encourages transportation enterprises to use artificial intelligence and $5 \mathrm{G}$ to speed up the spread of smart transportation and develop low-carbon transportation. Specifically, smart transportation enterprises can accelerate the development of green transportation, strengthen green infrastructure construction, promote the use of green and digital transport equipment, and encourage green travel [9-11]. However, how to reduce the carbon emission of transportation enterprises is the top priority. We attempt to explore the optimal strategies of smart transportation enterprises on green innovation. Therefore, our study may provide suggestions for effectively controlling the carbon emission of the transportation industry and realizing the aim of carbon emissions peak and neutrality.

However, enterprises are risk-averse, seeking a balance between green investment and benefit maximization. In many cases, they invest in green innovation technology but do not get enough benefits. Therefore, to weaken the external impact brought by green innovation, the governments must take effective measures to encourage transportation enterprises to introduce green technology innovation. The governments intervene in the green innovation behavior of transportation enterprises through effective environmental policies, such as innovation subsidies and carbon taxes [12-15].

Based on the evolutionary game, we have the following questions:

(1) Should the governments provide some subsidies or supports (levy some punitive taxes) to transportation enterprises to promote green technology innovation?

(2) What are the green innovation strategies adopted by transportation enterprises under various punitive taxes and subsidies mechanisms?

(3) Which mechanism is most suitable to encourage enterprises to introduce green technology innovation, the punitive taxes or subsidies?

In answer to the above questions, this paper constructed an evolutionary game model of the governments and smart transportation enterprises to explore the impact of governments policies on the enterprises' innovation strategies. Our key contribution lies in the following three aspects. First, the governments and enterprises are considered under the premise of bounded rationality. Second, we derived the ESS of the governments and enterprises under different scenarios. Third, we focused on the impact of the intensity of different governments policies (i.e., supply-oriented, demand-oriented, and environmental policies) on the green innovation strategies of enterprises. Therefore, our research can not only provide guidance for the governments to implement low-carbon policies but also provide suggestions for enterprises to adopt green technology innovation.

The rest is organized as follows: Section 2 reviews the literature on three streams related to this paper. Section 3 describes the problem and puts forward some assumptions. Section 4 constructs the evolutionary game model of the governments and smart transportation enterprises and presents the evolutionary stable strategies under different scenarios. Section 5 conducts a numerical simulation and discusses the impact of governments policies on the innovation strategies of enterprises. Section 6 presents our conclusions.

\section{Literature Review}

The study is mainly related to three streams: green technology innovation, the general game to study governments' and enterprises' behaviors, and the evolutionary game to study governments' and enterprises' behaviors.

2.1. Green Technology Innovation. To avoid or decrease ecological environment pollution and damage, many enterprises have begun to introduce green technology innovation, especially in the transportation industry. The goal of traditional technology innovation is mainly to bring economic benefits to enterprises, while green technology innovation emphasizes the comprehensive benefits of the economy, environment, and society.

Some scholars used empirical studies to explore how green innovation affect the enterprises' development [16-20]. Xie et al. explored how the green innovation affected the firms' financial performance and proved that the latter has a positive effect on the former [21]. Similarly, Wang et al. proved that enterprises can achieve higher economic performance by introducing green innovation [22]. Chen et al. proved that this positive effect also exists in enterprises' corporate competitive advantage [23]. Chang derived that green innovation is regarded as a mediating role in the positive relationship between corporate environmental ethics and competitive advantage [24]. Shen et al. proved that green creativity and green product development performance benefit from proactive green innovation, and green creativity can help enterprises achieve higher green product development performance [25].

Furthermore, some scholars explored the optimal green innovation strategy by game theory $[26,27]$. Yang and Wang constructed a game model and derived both manufacturers so that retailers can benefit from green innovation [28]. Wang et al. explored the optimal member to undertake the green technology innovation and found that the retailer is the more effective undertaker for green innovation [29]. Chen et al. modeled the optimal green investment cooperation strategies in a supply chain and examined how green cooperation affects the performances of the supply chain [30]. Shi et al. investigated the green technology investment in a competitive environment, which consists of one manufacturer and two retailers [31]. Yang et al. studied the 


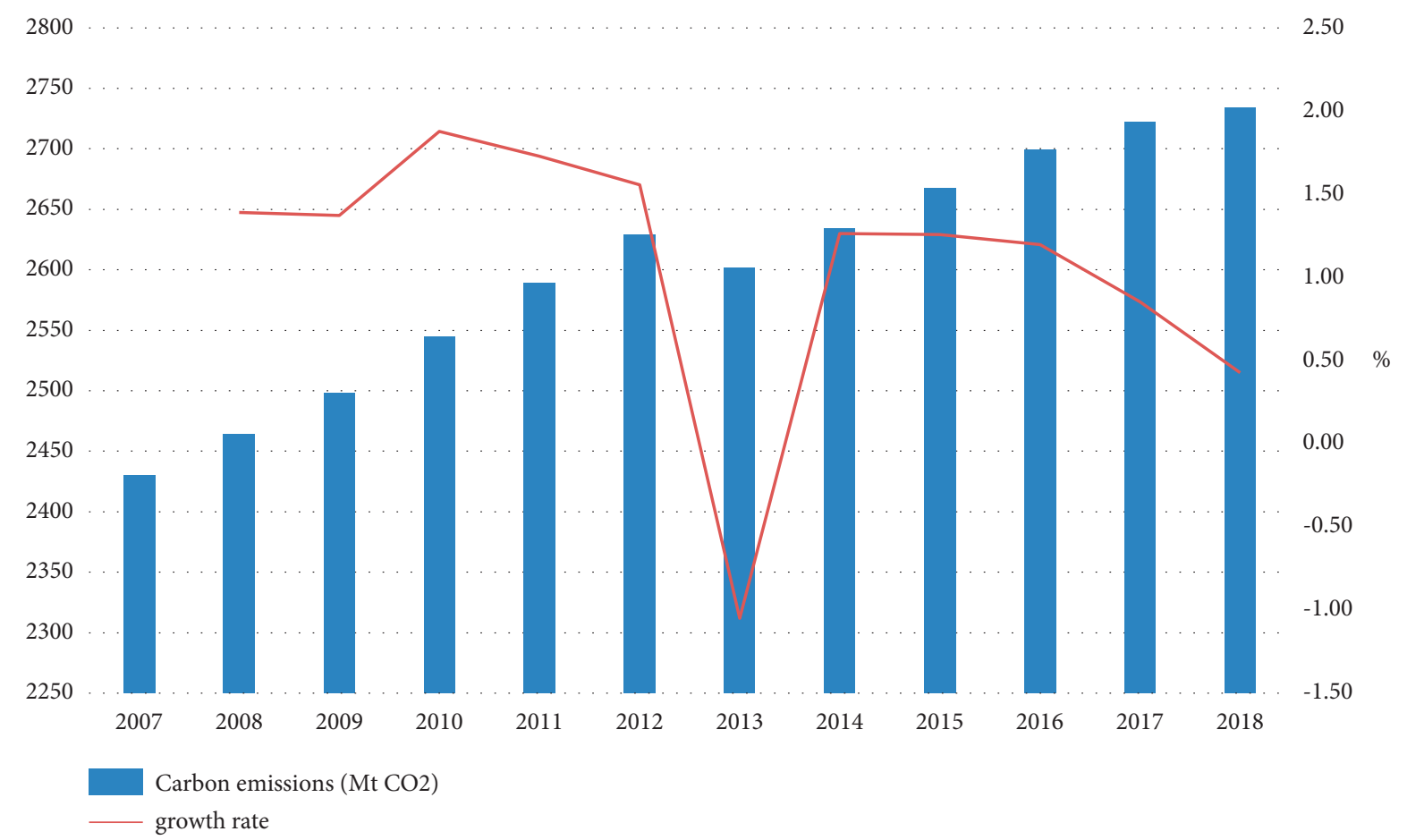

FIgURE 1: Carbon emissions and growth rate of China's transportation industry from 2007 to 2018.

green investment in a supply chain including two manufacturers [32]. The above literature focuses on the firms' green innovation decisions but ignores the impact of the governments on green innovation. Therefore, we contributed to this by further addressing how the governments' policies affect the green innovation strategies of enterprises.

\subsection{The General Game to Study Government and Enterprise} Behavior. In recent years, the governments have formulated some policies to intervene in the behavior of enterprise, which has attracted the attention of scholars. Li et al. explored the governments' optimal green subsidy mechanism and revealed that the governments can not always benefit from green subsidies [33]. Ma et al. explored the optimal green level under the governments' subsidies and cooperative contracts and derived that subsiding the manufacturer and retailer simultaneously can achieve a higher green level [34]. Liu et al. considered the case in which firms' innovation information cannot be completed observed and explored the green innovation strategies under subsidy policies [35]. Meng et al. modeled three cases of innovation subsidy and found that the government benefits from only subsidizing the manufacturer [36]. Deng et al. used Stackelberg game theory to model two cases: with and without political competition and derived the enterprises' green technology strategies in these cases [37]. Wang et al. simulated the equilibrium level under five different situations and found that government policies can remarkably improve the green technology innovation's level [38]. Gao and Ma analyzed the impact of the government's communication security regulation on the innovation decision-making of communication enterprises [39].
Considering that firms can benefit from green investment in reputations and competitiveness, Zhang et al. examined how the government subsidy affects green investment strategies and derive the optimal subsidy strategies [40]. Zhang and Yousaf found that green technology investment, consumers green preferences, and government intervention affect the optimal improvement degree [41]. Ma et al. examined the optimal investment level and cooperation modes in a supply chain and explored how the government policies affect firms' decisions [42]. Wu et al. analyzed the optimal technology investment decisions in a green supply chain under government subsidies and found that subsidy policies have a positive effect on the firms' green investment [43].

Based on the above literature, we can see that they formulate game models to study the impact of government intervention on enterprises' decisions. However, compared with the assumption that participants are perfectly rational in the game theory, the evolutionary game model is more realistic due to its assumption of bounded rationality.

2.3. The Evolutionary Game to Study Government and Enterprise Behavior. Many scholars used evolutionary game theory to explore the dynamic process of group evolution and examine how groups reach a stable state. For example, Zhang et al. explored how tax and subsidy affect manufacturers' green innovation strategies by an evolutionary game and found out the conditions for manufacturers' stable strategies [44]. Using the evolutionary game, Yang et al. and Deng et al. revealed that the green innovation ecosystem becomes more stable as the governments' penalty costs and subsidies increase [45]. Wang et al. explored the 
evolutionary process among three parts, including the governments, firms, and consumers, and analyzed how the participants' strategies influence the equilibrium [46]. Chai et al. modeled the evolutionary process between the governments and two manufacturers and pointed out which factors affect their cooperative choices [47]. Sun and Zhang built two evolutionary models under two mechanisms, including punishment and subsidy, discussed the evolutionary process of players, and derived the ESS of these models [48]. Guo et al. studied the evolutionary process among governments, institutions, and enterprises and analyzed these three elements' influence on strategic choice [49]. Xiao et al. explored the evolutionary process among governments, enterprises, institutions, aiming to get the conditions under which enterprises introduce independent innovation and collaborative innovation with the support of green finance [50].

The above literature mainly focuses on the green innovation of industrial enterprises and few strategic studies on transportation enterprises. Moreover, it is not clear how the intensity of government policies affects enterprise decisions. Therefore, we explored the evolutionary process between the governments and transportation enterprises and examined the impact mechanism of government behavior on green technology innovation of transportation enterprises.

\section{Problem Description and Assumption}

3.1. Problem Description. There are two game groups in this game system: the governments and smart transportation enterprises. The governments have two strategies for green innovation: intervention and no intervention. The strategy set of the governments is intervene, not-intervene\}. The intervention policies mainly include incentives for positive cooperation and punishment for negative cooperation. Incentives refer to financial subsidies, government procurement, talent support, and others, while punishment mainly refers to punitive taxes. The nonintervention refers to no measures to intervene enterprises' green innovation. That is, the enterprises can behave freely.

When there is a positive cooperative relationship between the governments and enterprises, the governments will take a series of supportive actions. Specifically, the cycle of green innovation of enterprises is long and the risk is high, hence enterprises who are short-sighted may not implement green innovation. The governments aiming at maximizing social welfare will formulate some incentive policies to support green innovation. In addition, when green innovation is necessary for enterprises, the governments will provide incentives to enterprises to increase their innovation income and strengthen their green innovation behavior.

When there is a negative cooperation relationship between the governments and enterprises, the governments will take punitive actions. Specifically, considering that enterprises only focus on their interests and ignore social welfare, the governments have the obligation and responsibility to formulate regulatory policies to restrict the environmental pollution of enterprises and force them to carry out green innovation.
Moreover, smart transportation enterprises have two different strategies for green innovation. The first one is a strategy where enterprises adopt green innovation and the second strategy is that enterprises adopt no green innovation. The strategy set of enterprises is \{adopt, not-adopt . The adoption means that enterprises provide financial support, professional personnel, and material resources to achieve green innovation. The nonadoption means that enterprises do not carry out any measures to reduce carbon emissions.

When making decisions, enterprises mainly consider their costs and benefits, which makes that they often lack public morality and social responsibility and pay attention to their own profits. This short-sighted behavior will lead to the conflict between enterprises' profits and public interests. Moreover, most enterprises hold a negative attitude to green innovation due to its high barriers and $\mathrm{R} \& \mathrm{D}$ costs. However, enterprises can benefit from green innovation in product type and quality, brand awareness, and social image, further developing rapidly and occupying more markets. For enterprises with high pollution and energy consumption, they cannot meet the environmental needs of the public, which may have an immediate negative impact on their reputation. Therefore, enterprises need to introduce green innovation to achieve higher profits.

3.2. Related Notations and Assumptions. To clearly describe the evolutionary game model, we show the related notations in Table 1.

We mainly study the evolutionary behavior of governments and enterprises. Hence, we consider the following modeling assumptions.

Assumption 1. The governments and enterprises are limited rationality, have certain learning abilities and evolution, and behave independently [51-55].

Assumption 2. There are two strategies for the governments on green innovation. The set of strategies is $G=\{$ intervene, not - intervene $\}$. We use I and NI to denote these two strategies. Among them, the probability that the governments choose strategy I is $x$, and the probability that the governments choose strategy NI is $1-x$. Moreover, there are two strategies for enterprises on green innovation. The set of strategies is $E=\{$ adopt, not - adopt $\}$. We use A and NA to denote these two strategies. The probability of introducing strategy $\mathrm{A}$ is $y$, and the probability of introducing strategy NA is $1-y$. In addition, we assume $x$ and $y$ are related to time $t$, and satisfy $0 \leq x, y \leq 1$. After continuous learning, the governments and transportation enterprises reach the evolutionary stability strategy (ESS) [56-58]. We use $x^{*}$ and $y^{*}$ to denote the selection probability of the governments and enterprises under ESS.

Assumption 3. The governments implement some supportive policies to guide the green technology innovation of transportation enterprises. Policy tools are mainly divided into three types: supply-oriented, demand-oriented, and environment-oriented. We assume that the implementation intensity factors of supply-oriented, demand-oriented, and 
TABLE 1: Notations and symbols.

\begin{tabular}{lc}
\hline Symbols & Definitions \\
\hline$\alpha$ & Implementation intensity of supply-oriented policy instruments \\
$\gamma$ & Implementation intensity of demand-oriented policy tools \\
$A$ & Implementation intensity of environmental policy tools \\
$J$ & The cost of the governments on supply-oriented policy \\
$K$ & The cost of the governments on demand-oriented policy \\
$\delta$ & The cost of the governments on environmental policy \\
$R$ & Implementation intensity of punitive policies \\
$P$ & The cost of the governments on punitive policies \\
$C$ & The initial revenue of enterprises \\
$P$ & The cost of green innovation \\
$P_{g}$ & The increased revenue with green innovation \\
$\varepsilon$ & The revenue of enterprises' green innovation to the governments \\
$S_{g}$ & The revenue loss intensity of enterprises without green innovation \\
\hline
\end{tabular}

environmental policy tools are $\alpha, \beta$, and $\gamma$. The costs of adopting these policies are $A, J$, and $K$.

For the supply-oriented policy tools, the governments provide certain financial incentives to transportation enterprises through financial subsidies, bank loans, and other means. That is, transportation enterprises can enjoy certain financial subsidies for green technology innovation. Demand-based policy tools are used by the government to guide market demand through the governments' purchase of green technology innovative products. This part of the income is calculated in the total income of transportation enterprises. Environmental policy tool is a public product by which the governments will shape the green innovation environment. Under this assumption, the governments will provide certain supply-oriented financial subsidies $\alpha A$, demand-oriented market purchases $\beta J$, and environmental expenditure $\gamma K$. Therefore, the governments' expenditure under this condition is $\alpha A+\beta J+\gamma K$.

Assumption 4. The governments adopt punitive policies to restrict the behavior of transportation enterprises. For example, the governments impose punitive taxes, such as carbon taxes, to urge enterprises to implement green innovation. We assume that the costs for the governments to implement punitive behavior is $R$ and its execution intensity is $\delta$.

Assumption 5. For transportation enterprises, we assume that their initial revenue is $p$, their cost of green innovation is $C$, their additional revenue obtained after green innovation is $\Delta P$, which is higher than zero. Moreover, the revenue from enterprises' green innovation to the governments is $p_{g}$. If transportation enterprises choose strategy $\mathrm{NA}$, their revenue will decline. We use $\varepsilon$ to denote the decline intensity, and then the revenue received by enterprises without green technology innovation is $(1-\varepsilon) P$. The loss for the governments caused by no green innovation is $s_{g}$.

\section{An Evolutionary Game Model between Transportation Enterprises and Governments}

4.1. Evolutionary Game Model. Based on the analysis and assumptions of the relationship between government and enterprises, we can create the evolutionary game model. Table 2 shows the payoffs of these two groups under different strategies.

Let $U_{G}$ and $U_{\bar{G}}$ denote the governments' expected earnings of "Intervene" and "Not-intervene" for governments, which are shown as follows:

$U_{G}=y\left(P_{g}-\alpha A-\beta J-\gamma K\right)+(1-y)\left(\delta R-\gamma K-S_{g}\right)$,

$U_{\bar{G}}=y P_{g}+(1-y)\left(-S_{g}\right)$.

We use $\overline{U_{G}}$ to represent the governments' average earning, shown as follows:

$$
\overline{U_{G}}=x U_{G}+(1-x) U_{\bar{G}} .
$$

Let $U_{E}$ and $U_{\bar{E}}$ denote the enterprises' expected earnings of "Adopt" and "Not-adopt," which are shown as follows:

$$
\begin{aligned}
& U_{E}=x(P+\Delta P+\alpha A+\beta J-C)+(1-x)(P+\Delta P-C), \\
& U_{\bar{E}}=x[(1-\varepsilon) P-\delta R]+(1-x)(1-\varepsilon) P .
\end{aligned}
$$

We use $\overline{U_{E}}$ to denote the average earning of transportation enterprises, shown as follows:

$$
\overline{U_{E}}=y U_{E}+(1-y) U_{\bar{E}} .
$$

Based on the dynamic formulas of evolutionary game, we have the replicator dynamic equation of "Intervene" adopted by the manufacturer $F(x)$ and the replicator dynamic equation of "Adopt" chosen by enterprises $F(y)$ as follows: 
TABLE 2: Payoff matrix between governments and enterprises.

\begin{tabular}{lr}
\hline & $\begin{array}{c}\text { Governments } \\
\text { NI }(1-x) \\
\text { Enterprises }\end{array}$ \\
\hline$F(x)=\frac{\mathrm{d} x}{\mathrm{~d} t}=x\left(U_{G}-\overline{U_{G}}\right)=x(1-x)[-y(\alpha A+\beta J+\gamma K)+(1-y)(\delta R-\gamma K)]$, & $\begin{array}{c}P+\Delta P-C, P_{g} \\
1-\varepsilon P,-S_{g}\end{array}$ \\
$F(y)=\frac{\mathrm{d} y}{\mathrm{~d} t}=y\left(U_{E}-\overline{U_{E}}\right)=y(1-y)[x(\alpha A+\beta J+\delta R)-C+\varepsilon P+\Delta P]$. & $(5)$
\end{tabular}

The replicator dynamic equations of transportation enterprises and governments constitute an evolutionary game replication dynamic system, which is shown in the following equation:

$$
\left\{\begin{array}{l}
\frac{\mathrm{d} x}{\mathrm{~d} t}=x(1-x)[-y(\alpha A+\beta J+\gamma K)+(1-y)(\delta R-\gamma K)], \\
\frac{\mathrm{d} y}{\mathrm{~d} t}=y(1-y)[x(\alpha A+\beta J+\delta R)-C+\varepsilon P+\Delta P] .
\end{array}\right.
$$

4.2. Evolutionary Stability Analysis. In this section, we analyze the destination of the tripartite evolutionary game to

$$
\begin{aligned}
J & =\left[\begin{array}{ll}
\frac{\partial F(x)}{\partial x} & \frac{\partial F(x)}{\partial y} \\
\frac{\partial F(y)}{\partial x} & \frac{\partial F(y)}{\partial y}
\end{array}\right]=\left[\begin{array}{ll}
a & b \\
c & d
\end{array}\right] \\
= & {\left[\begin{array}{r}
(1-2 x)[-y(\alpha A+\beta J+\gamma K)+(1-y)(\delta R-\gamma K)] \\
y(1-y)(\alpha A+\beta J+\delta R)
\end{array}\right.}
\end{aligned}
$$

obtain the evolutionary stable strategy (ESS). When all the replication dynamic equations are equal to zero, we have the equilibrium points as follows.

Proposition 1. The equilibrium points of the replicator dynamic system are $(0,0),(0,1),(1,0),(1,1)$, and $\left(x_{0}, y_{0}\right)$, where $0 \leq x_{0} \leq 1, \quad 0 \leq y_{0} \leq 1, \quad$ and $x_{0}=[(C-\varepsilon P-\Delta P) /$ $(\alpha A+\beta J+\delta R)], y_{0}=[(\delta R-\gamma K) /(\alpha A+\beta J+\delta R)]$.

Proposition 1 presents the equilibrium points of the replicator dynamic system. However, the equilibrium points are not necessarily the ESS. Therefore, we need to examine the stability of the equilibrium points by the Jacobian matrix [46-49], which is shown as follows:
The equilibrium point is an ESS only when det $J=\left|\begin{array}{ll}a & b \\ c & d\end{array}\right|=a d-b c>0$ and $\operatorname{tr} \quad J=a+d<0 \quad$ [59-62]. Considering ESS is related to the values of $\alpha A, \beta J, \delta R, \gamma K$ and $C, \varepsilon P, \Delta P$, we discuss the equilibrium strategy in the cases of $\delta R-\gamma K / \alpha A+\beta J+\delta R<0$ and $0<\delta R-\gamma K / \alpha A+\beta$ $J+\delta R<1$, which is shown in Proposition 2. Tables 3 and 4 show the analysis.

Proposition 2. The evolutionary stable strategies are as follows:

(i) When $0<\delta R-\gamma K<\alpha A+\beta J+\delta R$ and $0<C-\varepsilon P-$ $\Delta P<\alpha A+\beta J+\delta R$, the replicator dynamic system has no ESS.

$$
\left.\begin{array}{c}
-x(1-x)(\alpha A+\beta J+\delta R) \\
(1-2 y)[x(\alpha A+\beta J+\delta R)-C+\varepsilon P+\Delta P]
\end{array}\right] .
$$

(ii) When $0<\delta R-\gamma K<\alpha A+\beta J+\delta R \quad$ and $C-\varepsilon P-\Delta P<0$, then $(0,1)$ is an ESS. The behavior strategy is (Not-intervene, Adopt).

(iii) When $0<\delta R-\gamma K<\alpha A+\beta J+\delta R \quad$ and $C-\varepsilon P-\Delta P>\alpha A+\beta J+\delta R$, then $(1,0)$ is an ESS. The behavior strategy is (Intervene, Not-adopt).

(iv) When $\delta R-\gamma K<0$ and $C-\varepsilon P-\Delta P<0$, then $(0,1)$ is an ESS. The behavior strategy is (Not-intervene, Adopt).

(v) When $\delta R-\gamma K<0$ and $0<C-\varepsilon P-\Delta P<$ $\alpha A+\beta J+\delta R$, then $(0,0)$ is an ESS. The behavior strategy is (Non-intervene, Not-adopt).

Proposition 2 presents the different ESS in the system, and Figure 2 shows the evolutionary path of the strategies 
TABLE 3: Local stability analysis between the governments and enterprises.

\begin{tabular}{|c|c|c|c|c|c|c|c|c|c|}
\hline \multirow[t]{3}{*}{ Strategy } & \multicolumn{9}{|c|}{$0<\delta R-\gamma K<\alpha A+\beta J+\delta R$} \\
\hline & \multicolumn{3}{|c|}{$0<C-\varepsilon P-\Delta P<\alpha A+\beta J+\delta R$} & \multicolumn{3}{|c|}{$C-\varepsilon P-\Delta P<0$} & \multicolumn{3}{|c|}{$C-\varepsilon P-\Delta P>\alpha A+\beta J+\delta R$} \\
\hline & $\operatorname{det} J$ & $\operatorname{tr} J$ & State & $\operatorname{det} J$ & $\operatorname{tr} J$ & State & $\operatorname{det} J$ & $\operatorname{tr} J$ & State \\
\hline$(0,0)$ & - & $\mathrm{N}$ & Saddle point & + & + & Instability point & - & - & Saddle point \\
\hline$(0,1)$ & - & $\mathrm{N}$ & Saddle point & + & - & ESS & - & + & Saddle point \\
\hline$(1,0)$ & - & $\mathrm{N}$ & Saddle point & - & + & Saddle point & + & - & ESS \\
\hline$(1,1)$ & - & $\mathrm{N}$ & Saddle point & - & - & Saddle point & + & + & Instability point \\
\hline$\left(x_{0}, y_{0}\right)$ & + & 0 & Central point & & & & less & & \\
\hline
\end{tabular}

The symbol "+" denotes greater than zero, “-” denotes less than zero, and "N" denotes uncertainty.

TABLE 4: Local stability analysis between the governments and enterprises.

\begin{tabular}{|c|c|c|c|c|c|c|c|c|c|}
\hline \multirow[t]{3}{*}{ Strategy } & \multicolumn{9}{|c|}{$\delta R-\gamma K<0$} \\
\hline & \multicolumn{3}{|c|}{$0<C-\varepsilon P-\Delta P<\alpha A+\beta J+\delta R$} & \multicolumn{3}{|c|}{$C-\varepsilon P-\Delta P<0$} & \multicolumn{3}{|c|}{$C-\varepsilon P-\Delta P>\alpha A+\beta J+\delta R$} \\
\hline & $\operatorname{det} J$ & $\operatorname{tr} J$ & State & $\operatorname{det} J$ & $\operatorname{tr} J$ & State & $\operatorname{det} J$ & $\operatorname{tr} J$ & State \\
\hline$(0,0)$ & + & - & ESS & - & $\mathrm{N}$ & Saddle point & + & - & ESS \\
\hline$(0,1)$ & - & - & Saddle point & + & - & ESS & - & $\mathrm{N}$ & Saddle point \\
\hline$(1,0)$ & + & + & Instability point & + & + & Instability point & - & $\mathrm{N}$ & Saddle point \\
\hline$(1,1)$ & - & + & Saddle point & - & $\mathrm{N}$ & Saddle point & + & + & Instability point \\
\hline$\left(x_{0}, y_{0}\right)$ & & $\mathrm{Me}$ & gless & + & 0 & Central point & + & 0 & Central point \\
\hline
\end{tabular}

The symbol "+" denotes greater than zero, “-" denotes less than zero, and "N" denotes uncertainty.

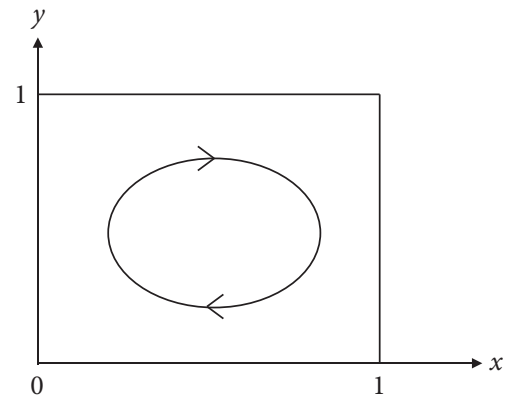

(a)

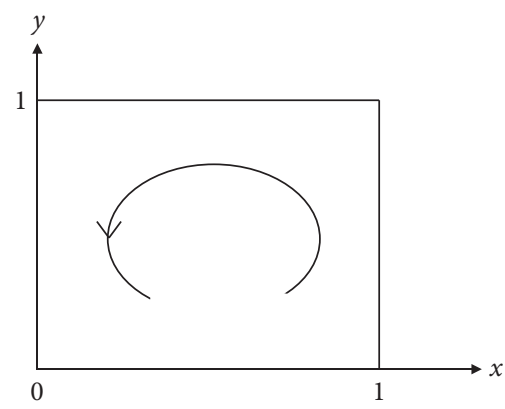

(d)

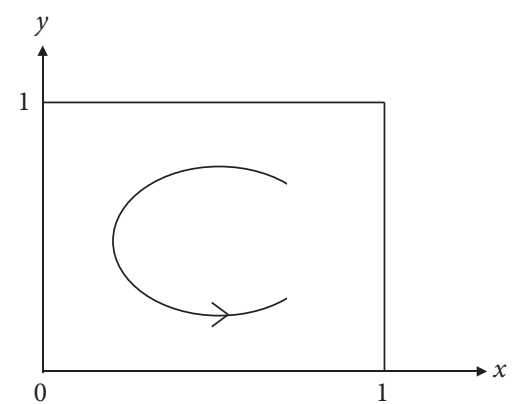

(b)

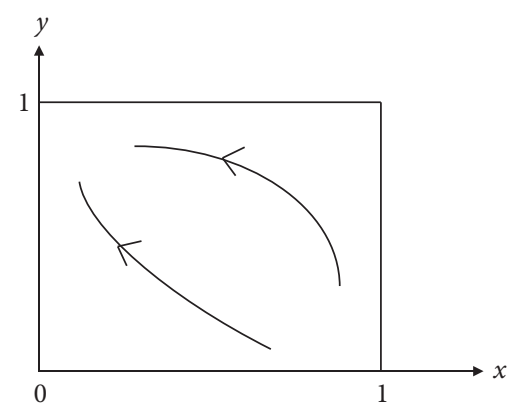

(e)

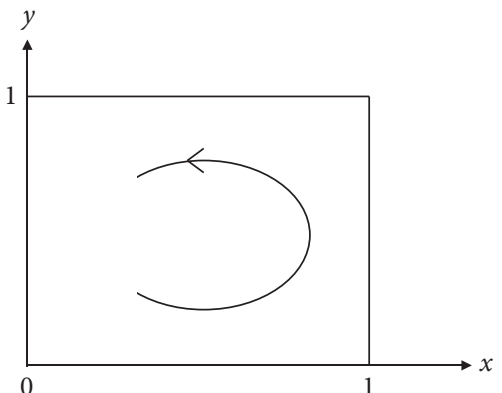

(c)

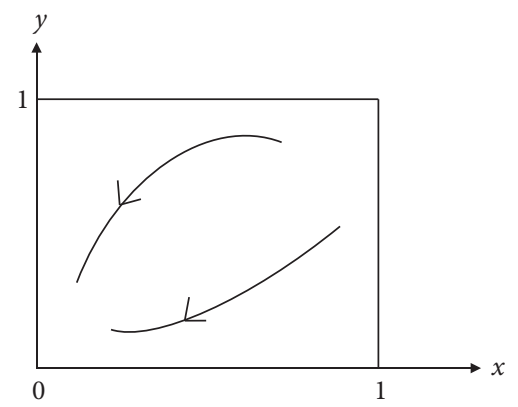

(f)

FIGURE 2: Local stability of the evolutionary game between the governments and enterprises.

chosen by the governments and enterprises under different conditions.

When $0<\delta R-\gamma K<\alpha A+\beta J+\delta R$ and $0<C-\varepsilon P-\Delta P<$ $\alpha A+\beta J+\delta R$, there is no ESS in the system and Figure $2(\mathrm{a})$ shows the evolutionary path. When $0<\delta R-\gamma K<\alpha A+\beta J+$ $\delta R$ and $C-\varepsilon P-\Delta P<0,(0,1)$ is the ESS of the replicator dynamic system, and Figure 2(b) shows the evolutionary path. When $0<\delta R-\gamma K<\alpha A+\beta J+\delta R$ and $C-\varepsilon P-\Delta$ $P>\alpha A+\beta J+\delta R,(1,0)$ is the ESS of the replicator dynamic system, and Figure 2(c) shows the evolutionary path. This means that if the punitive tax revenue from government intervention is higher than the environmental policy cost, the 
results of the evolutionary equilibrium between the governments and enterprises depend on the profit changes enterprises receive with and without green innovation (i.e., $\Delta P-C$ and $-\varepsilon P)$. When the profit change from green innovation is higher than that from not green innovation (i.e., $\Delta P-C>-\varepsilon P$ ), enterprises are more inclined to choose green innovation and the governments do not intervene the behavior of enterprises. Moreover, when the difference in profit changes between without and with green innovation is greater than the subsidies from the governments (i.e., $-\varepsilon P-(\Delta P-C)>\alpha A+\beta J+\delta R)$, enterprises have no motivation to implement green innovation. However, the governments are more inclined to intervene green innovation. Therefore, the governments cannot encourage enterprises to implement green innovation.

When $\delta R-\gamma K<0$ and $C-\varepsilon P-\Delta P<0,(0,1)$ is the ESS and Figure 2(d) shows the evolutionary path. When $\delta R-\gamma K<0$ and $0<C-\varepsilon P-\Delta P<\alpha A+\beta J+\delta R,(0,0)$ is the ESS and Figure 2(e) shows the evolutionary path. When $\delta R-$ $\gamma K<0$ and $C-\varepsilon P-\Delta P>\alpha A+\beta J+\delta R,(0,0)$ is the ESS, and Figure 2(f) shows the evolutionary path. This means that if the punitive tax revenue from government intervention is lower than the environmental policy cost, the governments are more inclined to not intervene in green innovation. The profit change enterprises receive from green innovation is lower than that from not green innovation; enterprises are unwilling to implement green innovation. This represents the worst scenario, and the way to solve this is to find a third party to create a green technology innovation environment to reduce the governments' intervention costs. If the profit change from not green innovation is lower than that from green innovation, enterprises are more inclined to implement innovation.

To summarize, we find that when the game players are only the governments and transportation enterprises, the behavior of the governments depends on the punitive tax revenue obtained by government supervision and the policy costs on environmental policy tools, and the behavior of enterprises depends on the profit changes brought from green innovation and not green innovation. This conclusion is more consistent with the facts. The governments should consider the financial balance when making policy interventions, and enterprises should take focus on the cost and benefit from green innovation.

\section{Simulations and Discussion}

We use MATLAB software to simulate the evolution game between the governments and enterprises under different policies and simulate different policy intensities to explore the impact of government policies on the green innovation strategies of transportation enterprises. Figures 3-5 show the evolution path of stable strategies of the governments and transportation enterprises, where $x$ and $y$ denotes the proportion of the governments' intervention on green innovation and the proportion of green innovation implemented by enterprises. The abscissa represents time $t$ and the ordinate represents the proportion of "intervene" and "adopt" strategies. We consider the following scenarios:
Scenario 1: when both the governments' incentive cost for green innovation and the benefits enterprises obtained from green innovation are high, we set the following parameter values: $\Delta P=4, \alpha=0.5, \beta=0.5$, $\gamma=0.5, \delta=0.5, \varepsilon=0.5, A=5, J=2, K=1, R=1$, $C=10$, and $P=15$. The state that the governments do not intervene in green innovation and enterprises implement green innovation becomes steady. The evolution path of the system is shown in Figure 3.

Scenario 2: when the governments' incentive cost for green innovation is high and the benefits enterprises obtained from green innovation are low, we set $\Delta P=2$. Other parameter values are equal to those in Scenario 1. The state that the governments do not intervene in green innovation and enterprises do not implement green innovation becomes steady. The evolution path of the system is shown in Figure 4.

Scenario 3: when both the governments' incentive cost for green innovation and the cost of green innovation implemented by enterprises are high, we set $C=12$. Other parameter values are equal to those in Scenario 1. The state that the governments do not intervene in green innovation and enterprises do not implement green innovation becomes steady. The evolution path of the system is shown in Figure 5.

In conclusion, we find that the governments and enterprises mainly consider their own costs and benefits on green innovation in the game. When the governments' incentive cost on green innovation, such as supply-oriented policy, demand-oriented policy, and environmental policy, is high, the governments tend to adopt the nonintervention strategy. When the cost of green innovation implemented by transportation enterprises is high or the benefits are low, they prefer to adopt the noninnovation strategy. The steadystate equilibrium strategy of Scenario 1 is an ideal state that can be achieved when the governments do not intervene in green innovation and enterprises implement green innovation. Therefore, this paper selects Scenario 1 as the initial scenario to analyze the evolution track of transportation enterprises' strategy under different policy intensity changes and explore the impact of the governments' policy tools on enterprises' strategy. Moreover, this paper referred to the statistical data of China Statistical Yearbook and the Ministry of Transport of the People's Republic of China, and the assumptions about the above parameters are also reasonable (Ministry of transport of the people's Republic of China: https://www.mot.gov.cn).

We conduct the simulation analysis under the cases where the governments' supply-oriented intensity is $0.1,0.5$, and 0.9 . Under these three supply-oriented policy intensities, the governments' nonintervention and enterprises' green innovation are stable strategies. Moreover, with the increase of the intensity of supply-oriented policies, the speed of reaching a stable state is faster. Therefore, the supply-oriented policy tools provided by the governments can accelerate the implementation of enterprises' green innovation. The evolution path of the system is shown in Figure 6. 


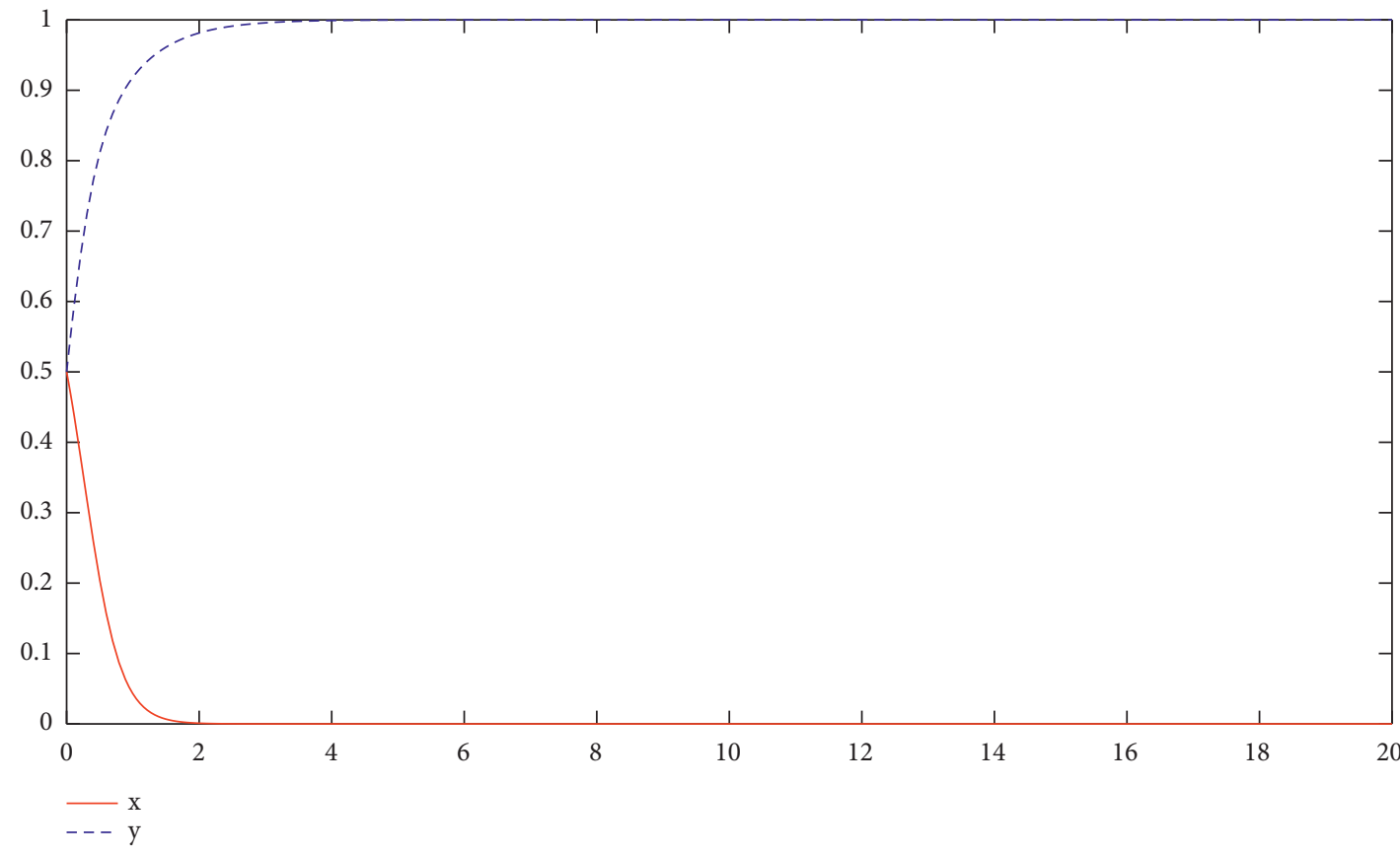

FIgURE 3: The evolution track of scenario 1.

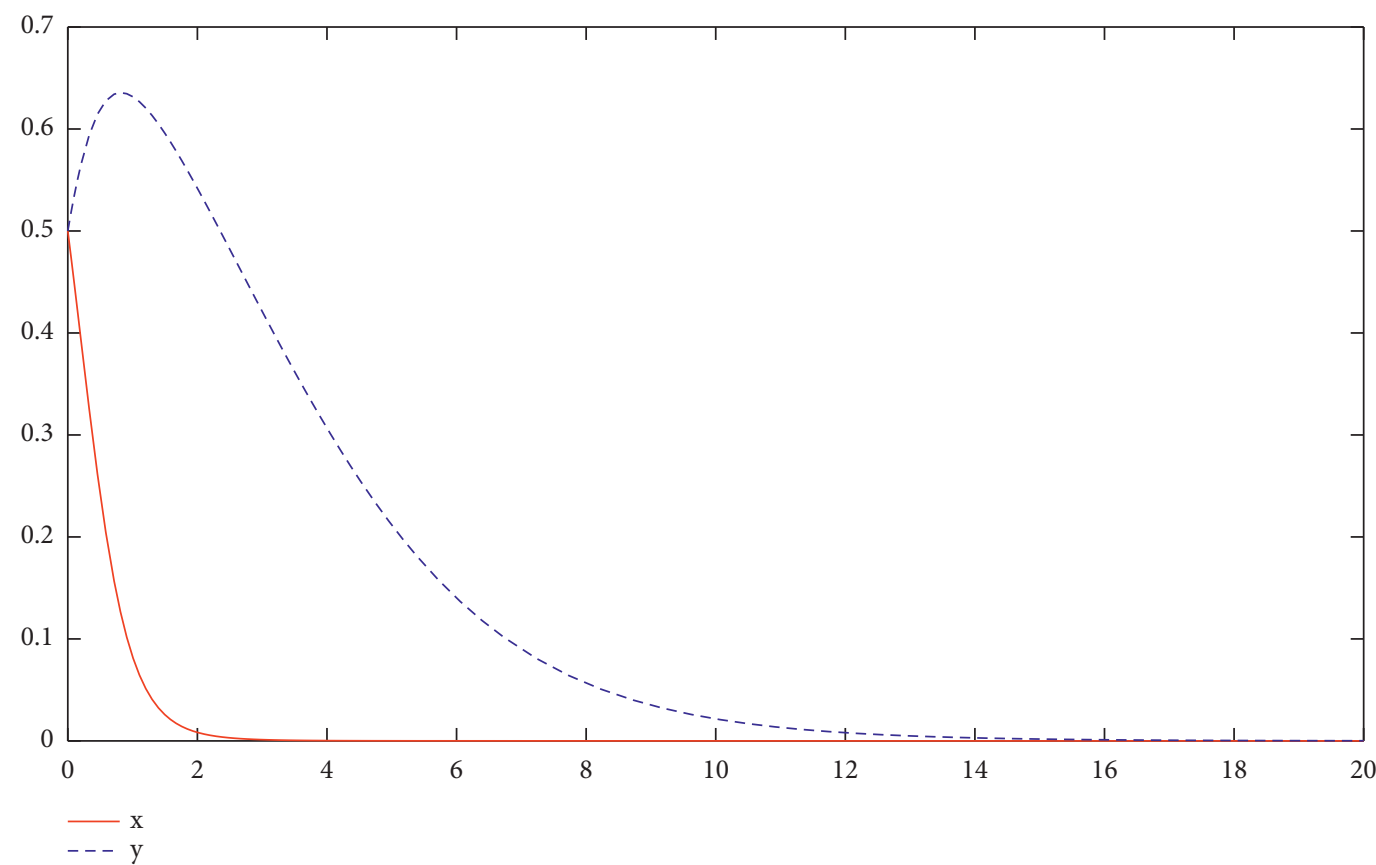

FIgURE 4: The evolution track of scenario 2.

We conducted the simulation analysis under the cases where the governments' demand-oriented intensity is 0.1 , 0.5 , and 0.9. Under these three demand-oriented policy intensities, the governments' nonintervention and enterprises' green innovation are stable strategies. Moreover, the speed of reaching a stable state is faster as the intensity of environmental policy increases. Therefore, demand-oriented policy tools can accelerate the implementation of enterprises' green innovation. The evolution path of the system is shown in Figure 7.

We also conducted the simulation analysis under the cases where the governments' environmental policy 


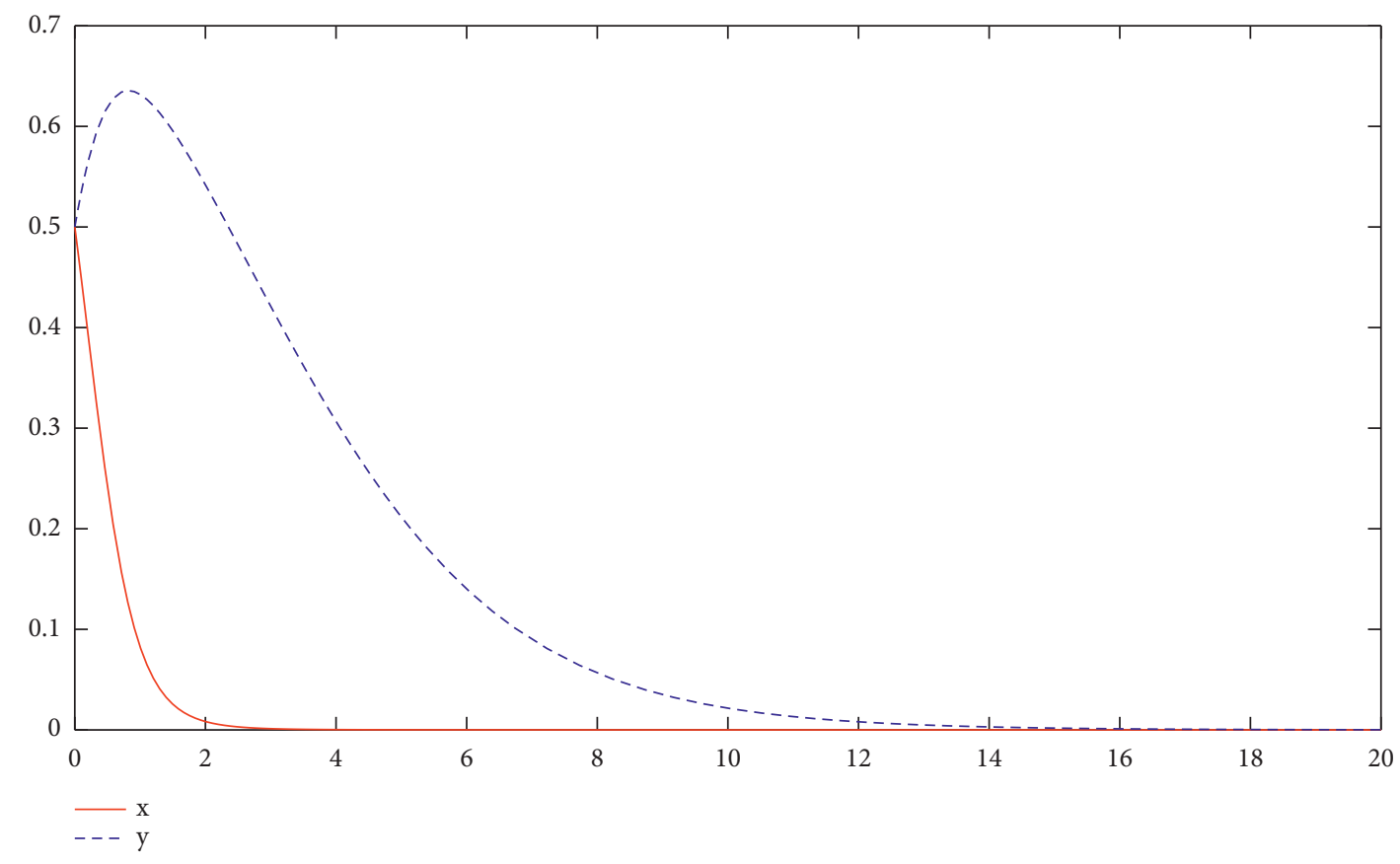

FIgURE 5: The evolution track of scenario 3.

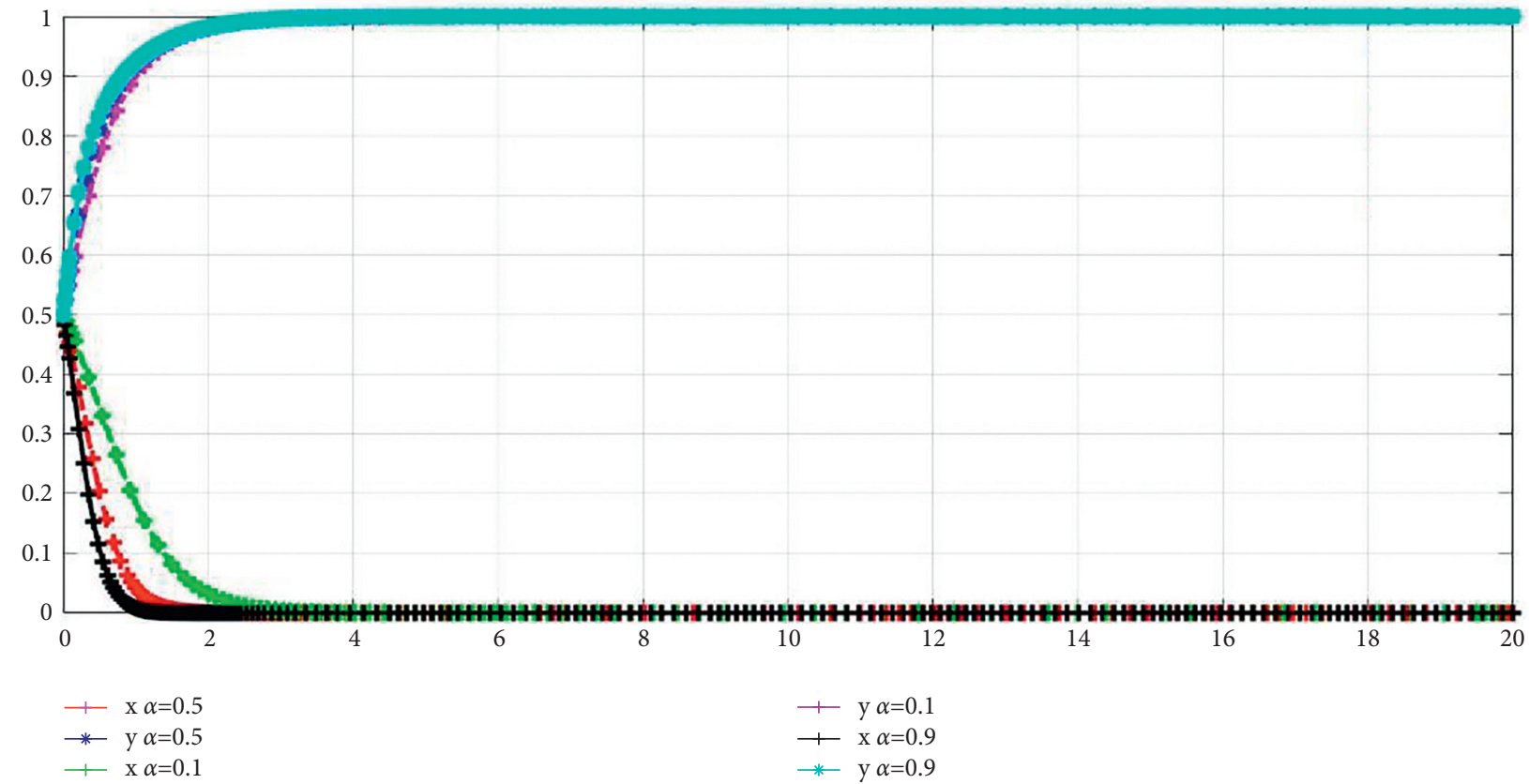

FIgURE 6: Evolution track of different supply-oriented policy intensities.

intensity is $0.1,0.5$, and 0.9 . Under these three environmental policy intensities, the governments' nonintervention and enterprises' green innovation are stable strategies. Moreover, with the increase of the intensity of environmental policy, the speed of reaching a stable state is faster. Therefore, environmental policy tools can accelerate green innovation. The system evolution path is shown in Figure 8 . 


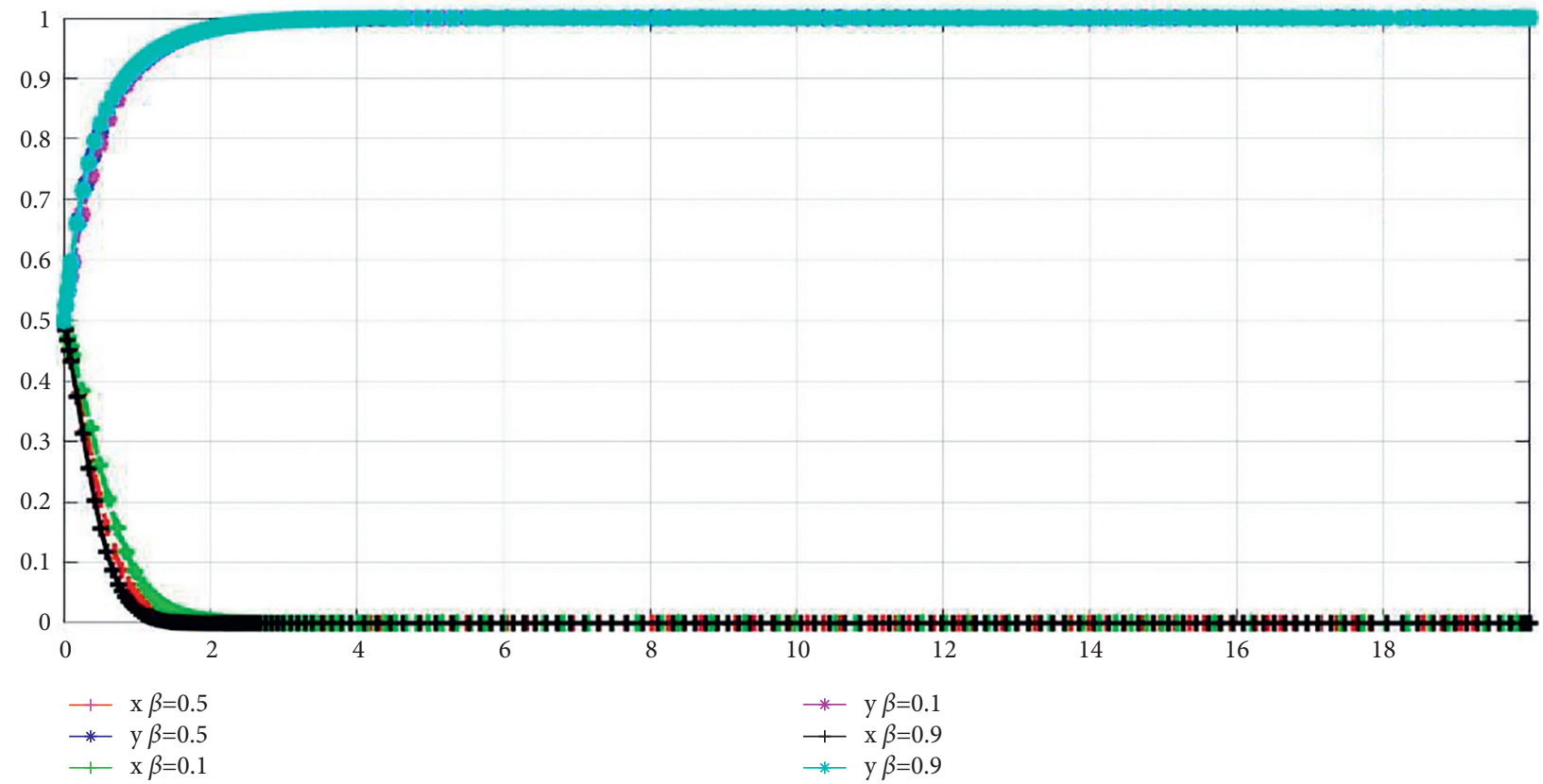

FIGURE 7: Evolution track of different demand-oriented policy intensities.

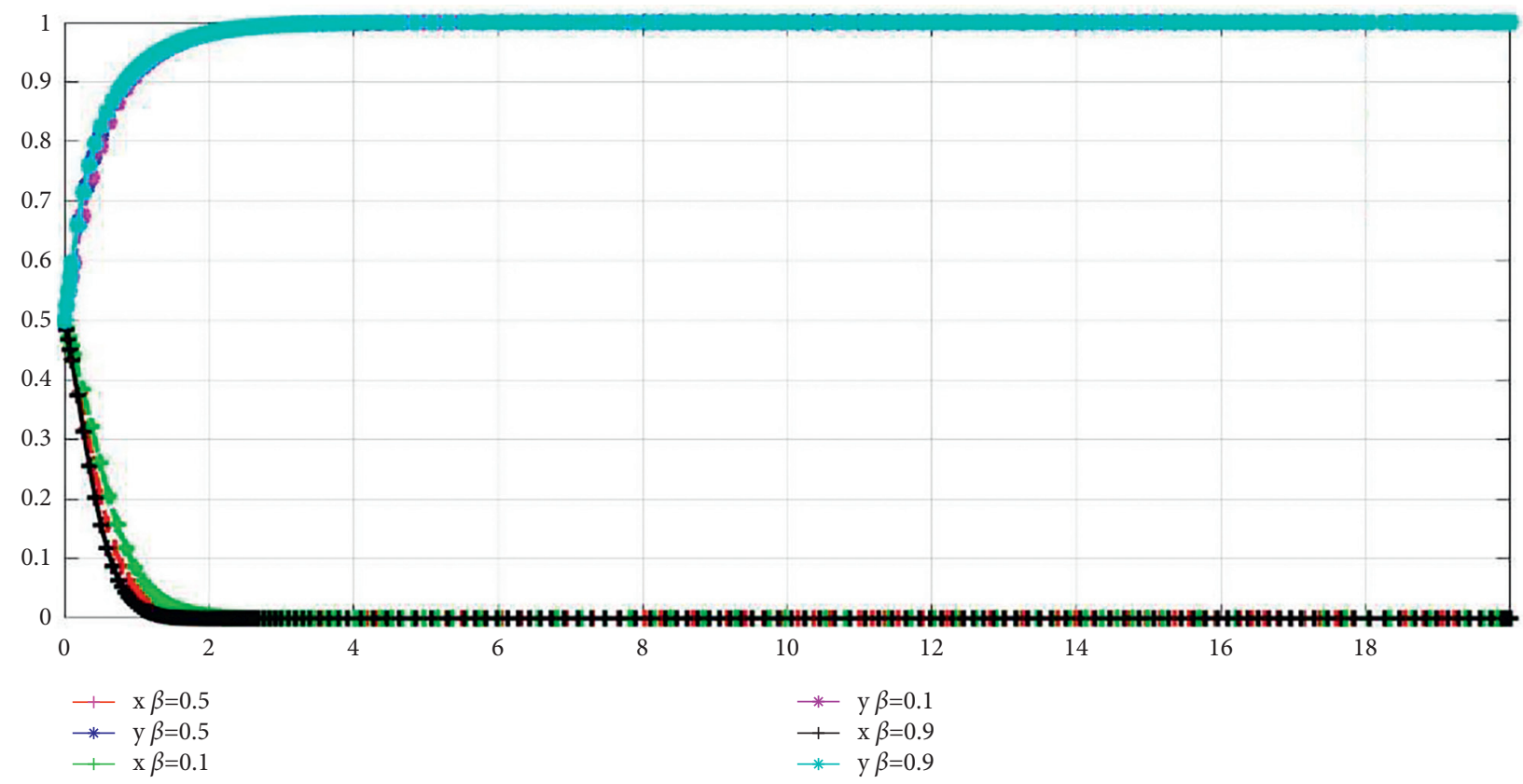

FIGURE 8: Evolution track of different environmental policy intensities.

\section{Conclusions}

In this study, we built an evolutionary model between the governments and smart transportation enterprises to explore the behavior of the two groups. Moreover, we simulated different costs and intensities of policy tools to analyze how the governments' policies affect the green innovation strategies of enterprises. We found that the behavior of the governments and enterprises depends on their own costs and benefits. Specifically, the behavior of the governments is based on the benefits of its supervision and the costs of supporting green technology innovation. The behavior of enterprises depends on the benefits of green innovation and the loss of no green innovation. With the increase of costs, participants will be less motivated to carry out green innovation, especially for enterprises. Moreover, different policy tools provided by the governments can accelerate the implementation of enterprises' green innovation.

From model analysis and numerical simulation, we got some key insights as follows. Firstly, when the profit is 
greater than the cost, smart transportation enterprises will take the initiative to carry out green innovation. However, the green innovation of smart transportation enterprises still needs the support of government policies. The government can improve the innovation initiative of smart transportation enterprises through the comprehensive application of supply-oriented, demand-oriented, and environmental policies. Secondly, because of the positive effect of environmental policies provided by the governments, it is necessary to reduce the costs of government intervention and increase the benefits of intervention to encourage the governments to fulfill their responsibilities. Third, it is beneficial to make enterprises fully use the smart technology spillover effect to reduce the costs of green innovation and improve the brand image of enterprises to increase the benefits brought by green innovation.

Future research may include the following directions. First, we can explore how the consumers preference for green products affect green innovation and explore the evolutionary process among governments, smart transportation enterprises, and consumers. We also can consider other government policies into the evolutionary game and use more realistic data to examine the influence of governments' policies on the enterprises' choices.

\section{Data Availability}

No data were used to support this study.

\section{Conflicts of Interest}

The authors declare that they have no conflicts of interest.

\section{Acknowledgments}

This research was funded by the Shanghai Sailing Program, under grant number 20YF1433800.

\section{References}

[1] J. Jiao, C. Chen, and Y. Bai, "Is green technology vertical spillovers more significant in mitigating carbon intensity? Evidence from Chinese industries," Journal of Cleaner Production, vol. 257, 2020.

[2] S. A. Sarkodie, A. N. Ajmi, F. F. Adedoyin, and P. A. Owusu, "Econometrics of anthropogenic emissions, green energybased innovations, and energy intensity across OECD countries," Sustainability, vol. 13, no. 8, 2021.

[3] D. Tbelmann and T. Wendler, "The impact of environmental innovation on carbon dioxide emissions," Journal of Cleaner Production, vol. 244, 2020.

[4] J. Zhang, L. Kang, H. Li, P. Ballesteros-Perez, and J. Zuo, "The impact of environmental regulations on urban green innovation efficiency: The case of Xi'an," Sustainable Cities and Society, vol. 57, 2020.

[5] Y. Luo, M. Salman, and Z. Lu, "Heterogeneous impacts of environmental regulations and foreign direct investment on green innovation across different regions in China," The Science of the Total Environment, vol. 759, 2021.

[6] X. Ouyang, Q. Li, and K. Du, "How does environmental regulation promote technological innovations in the industrial sector? Evidence from Chinese provincial panel data," Energy Policy, vol. 139, 2020.

[7] M. Umar, D. Kirikkaleli, and A. A. Alola, "The imperativeness of environmental quality in the United States transportation sector amidst biomass-fossil energy consumption and growth," Journal of Cleaner Production, vol. 285, 2021.

[8] A. Rehman, H. Ma, I. Ozturk, M. Murshed, and V. Dagar, The Dynamic Impacts of CO2 Emissions from Different Sources on Pakistan's Economic Progress: A Roadmap to Sustainable Development, Environment Development and Sustainability, Berlin, Germany, pp. 1-24, 2021.

[9] E. Demir, T. Bektaş, and G. Laporte, "A review of recent research on green road freight transportation," European Journal of Operational Research, vol. 237, no. 3, pp. 775-793, 2014.

[10] J. Meckling and J. Nahm, "The politics of technology bans: industrial policy competition and green goals for the auto industry," Energy Policy, vol. 126, pp. 470-479, 2019.

[11] A. Sharifi, "Co-benefits and synergies between urban climate change mitigation and adaptation measures: a literature review," The Science of the Total Environment, vol. 750, 2021.

[12] J. Korhonen, S. Pätäri, A. Toppinen, and A. Tuppura, "The role of environmental regulation in the future competitiveness of the pulp and paper industry: the case of the sulfur emissions directive in Northern Europe," Journal of Cleaner Production, vol. 108, pp. 864-872, 2015.

[13] B. Yuan and Q. Xiang, "Environmental regulation, industrial innovation and green development of Chinese manufacturing: based on an extended CDM model," Journal of Cleaner Production, vol. 176, pp. 895-908, 2018.

[14] J. Hussain, Y. Pan, G. Ali, and X. Yue, "Pricing behavior of monopoly market with the implementation of green technology decision under emission reduction subsidy policy," The Science of the Total Environment, vol. 709, 2020.

[15] F. Fan, H. Lian, X. Liu, and X. Wang, "Can environmental regulation promote urban green innovation Efficiency? An empirical study based on Chinese cities," Journal of Cleaner Production, vol. 287, no. 1, 2021.

[16] K. Du and J. Li, “Towards a green world: how do green technology innovations affect total-factor carbon productivity," Energy Policy, vol. 131, pp. 240-250, 2019.

[17] G. Li, M. K. Lim, and Z. Wang, "Stakeholders, green manufacturing, and practice performance: empirical evidence from Chinese fashion businesses," Annals of Operations Research, vol. 290, no. 1-2, pp. 961-982, 2020.

[18] D. Zhang, Z. Rong, and Q. Ji, "Green innovation and firm performance: evidence from listed companies in China," Resources, Conservation and Recycling, vol. 144, pp. 48-55, 2019.

[19] D. De, S. Chowdhury, P. K. Dey, and S. K. Ghosh, "Impact of lean and sustainability oriented innovation on sustainability performance of small and medium sized enterprises: a data envelopment analysis-based framework," International Journal of Production Economics, vol. 219, pp. 416-430, 2020.

[20] Y. Sun and H. Sun, "Green innovation strategy and ambidextrous green innovation: the mediating effects of green supply chain integration," Sustainability, vol. 13, no. 9, p. $4876,2021$.

[21] X. Xie, J. Huo, and H. Zou, "Green process innovation, green product innovation, and corporate financial performance: a content analysis method," Journal of Business Research, vol. 101, pp. 697-706, 2019.

[22] M. Wang, Y. Li, J. Li, and Z. Wang, "Green process innovation, green product innovation and its economic 
performance improvement paths: a survey and structural model," Journal of Environmental Management, vol. 297, no. 1, 2021.

[23] Y. Chen, S. Lai, and C. Wen, "The influence of green innovation performance on corporate advantage in Taiwan," Journal of Business Ethics, vol. 67, no. 4, pp. 331-339, 2021.

[24] C.-H. Chang, "The influence of corporate environmental ethics on competitive advantage: the mediation role of green innovation," Journal of Business Ethics, vol. 104, no. 3, pp. 361-370, 2011.

[25] Y. Shen, T. Chang, C. Lin, P. Lai, and K. Wang, "The influence of proactive green innovation and reactive green innovation on green product development performance: the mediation role of green creativity," Sustainability, vol. 8, no. 10, p. 996, 2016.

[26] J. Zhang, R. Dai, Q. Zhang, and W. Tang, "An optimal energy efficiency investment and product pricing strategy in a twomarket framework," IEEE Transactions on Systems, Man, and Cybernetics: Systems, vol. 48, no. 4, pp. 608-621, 2018.

[27] X. Hao and B. Li, "Research on collaborative innovation among enterprises in green supply chain based on carbon emission trading," Science Progress, vol. 103, no. 2, Article ID 36850420916329, 2020.

[28] M. Yang and J. Wang, "Pricing and green innovation decision of green supply chain enterprises," International Journal of Technology Management, vol. 85, no. 2-4, pp. 127-141, 2021.

[29] S. Wang, Y. Cheng, X. Zhang, and C. Zhu, "The implications of vertical strategic interaction on green technology investment in a supply chain," Sustainability, vol. 12, no. 18, p. 7441, 2020.

[30] X. Chen, X. Wang, and M. Zhou, "Firms' green R\&D cooperation behaviour in a supply chain: technological spillover, power and coordination," International Journal of Production Economics, vol. 218, pp. 118-134, 2019.

[31] X. Shi, C. Dong, C. Zhang, and X. Zhang, "Who should invest in clean technologies in a supply chain with competition?" Journal of Cleaner Production, vol. 215, pp. 689-700, 2019.

[32] S. Yang, P. Ding, G. Wang, and X. Wu, "Green investment in a supply chain based on price and quality competition," Soft Computing, vol. 24, no. 4, pp. 2589-2608, 2020.

[33] Y. Li, Y. Tong, F. Ye, and J. Song, "The choice of the government green subsidy scheme: innovation subsidy vs. product subsidy," International Journal of Production Research, vol. 58, no. 16, pp. 4932-4946, 2020.

[34] W. Ma, R. Zhang, and S. Chai, "What drives green innovation? A game theoretic analysis of government subsidy and cooperation contract," Sustainability, vol. 11, no. 20, p. 5584, 2019.

[35] Y. Liu, H. Xu, and X. Wang, "Government subsidy, asymmetric information and green innovation," Kybernetes, vol. 51, no. 1, 2021.

[36] Q. Meng, Y. Wang, Z. Zhang, and Y. He, "Supply chain green innovation subsidy strategy considering consumer heterogeneity," Journal of Cleaner Production, vol. 281, 2021.

[37] Y. Deng, D. You, and J. Wang, "Optimal strategy for enterprises' green technology innovation from the perspective of political competition," Journal of Cleaner Production, vol. 235, pp. 930-942, 2019.

[38] M. Wang, Z. Cheng, Y. Li, J. Li, and K. Guan, "Impact of market regulation on economic and environmental performance: a game model of endogenous green technological innovation," Journal of Cleaner Production, vol. 277, 2020.

[39] K. Gao and L. Ma, "Security regulation and enterprise innovation in communication industry," Security and
Communication Networks, vol. 202111 pages, Article ID 3307493, 2021.

[40] X. Zhang, T. Chen, and C. Shen, "Green investment choice in a duopoly market with quality competition," Journal of Cleaner Production, vol. 276, no. 3, 2020.

[41] X. Zhang and H. Yousaf, "Green supply chain coordination considering government intervention, green investment, and customer green preferences in the petroleum industry," Journal of Cleaner Production, vol. 246, 2020.

[42] S. Ma, Y. He, R Gu, and S. Li, "Sustainable supply chain management considering technology investments and government intervention," Transportation Research Part E: Logistics and Transportation Review, vol. 149, 2021.

[43] H. Wu, B. Xu, and D. Zhang, "Closed-loop supply chain network equilibrium model with subsidy on green supply chain technology investment," Sustainability, vol. 11, no. 16, Article ID 4403, 2019.

[44] S. Zhang, Y. Yu, Q. Zhu, C. M. Qiu, and A. Tian, "Green innovation mode under carbon tax and innovation subsidy: an evolutionary game analysis for portfolio policies," Sustainability, vol. 12, no. 4, Article ID 1385, 2020.

[45] Z. Yang, H. Chen, L. Du, C. Lin, and W. Lu, "How does alliance-based government-university-industry foster cleantech innovation in a green innovation ecosystem," Journal of Cleaner Production, vol. 283, 2021.

[46] M. Wang, Y. Li, Z. Cheng, C. Zhong, and W. Ma, "Evolution and equilibrium of a green technological innovation system: simulation of a tripartite game model," Journal of Cleaner Production, vol. 278, 2021.

[47] J. Chai, X. Xu, J. Xu, and X. Lyu, "Research on green collaborative innovation mechanism of cloud manufacturing enterprises under government supervision," Mathematical Problems in Engineering, vol. 202117 pages, Article ID 8820791, 2021.

[48] Z. Sun and W. Zhang, "Do government regulations prevent greenwashing? An evolutionary game analysis of heterogeneous enterprises," Journal of Cleaner Production, vol. 231, pp. 1489-1502, 2019.

[49] Y. Guo, H. Zou, and Z. Liu, "Behavioral analysis of subjects for green technology innovation: a tripartite evolutionary game model," Mathematical Problems in Engineering, vol. 2021, Article ID 5181557, 14 pages, 2021.

[50] H. Xiao, H. Tang, and J. Zhou, "On the LCEFT multi-player collaborative innovation evolutionary game with the support of green finance," Ekoloji, vol. 28, no. 107, pp. 1349-1364, 2019.

[51] K. Liu, H. Zhou, Y. Kou, J. Zhang, X. Zhou, and X. Zhang, "Simulation study on passive buildings' demand incentive based on evolutionary game," Journal of Intelligent and Fuzzy Systems, vol. 37, no. 3, pp. 31163-33174, 2019.

[52] Y. Liu, D. Cai, C. Guo, and H. Huang, "Evolutionary game of government subsidy strategy for prefabricated buildings based on prospect theory," Mathematical Problems in Engineering, vol. 2020, Article ID 8863563, 10 pages, 2020.

[53] X. Guo and Y. Zhang, "The system dynamics (SD) analysis of the government and power producers' evolutionary game strategies based on carbon trading (CT) mechanism: a case of China," Sustainability, vol. 10, no. 4, 2018.

[54] Y. Yang and W. Yang, "Does whistleblowing work for air pollution control in China? A study based on three-party evolutionary game model under incomplete information," Sustainability, vol. 11, no. 2, 2019.

[55] W. Liu and J. Yang, "The evolutionary game theoretic analysis for sustainable cooperation relationship of collaborative innovation 
network in strategic emerging industries," Sustainability, vol. 10, no. 12, 2018.

[56] J. Li, W. Du, F. Yang, and G. Hua, "Evolutionary game analysis of remanufacturing closed-loop supply chain with asymmetric information," Sustainability, vol. 6, no. 9, pp. 6312-6324, 2014.

[57] W. Fan, S. Wang, X. Gu, Z. Zhou, Y. Zhao, and W. Huo, "Evolutionary game analysis on industrial pollution control of local government in China," Journal of Environmental Management, vol. 298, 2021.

[58] X. Nie, J. Zhang, and L. Yang, "Research on evolution of collaboration mechanism of stakeholders in mining enterprises' implementation of social responsibility," RAIRO Operations Research, vol. 55, pp. S79-S95, 2021.

[59] C. Liu, W. Huang, and C. Yang, "The evolutionary dynamics of China's electric vehicle industry - taxes vs. subsidies," Computers \& Industrial Engineering, vol. 113, pp. 103-122, 2017.

[60] Q. Long, X. Tao, Y. Shi, and S. Zhang, "Evolutionary game analysis among three green-sensitive parties in green supply chains," IEEE Transactions on Evolutionary Computation, vol. 25, no. 3, pp. 508-523, 2021.

[61] Q. Li, H. Bao, Y. Peng, H. Wang, and X. Zhang, "The collective strategies of major stakeholders in land expropriation: a tripartite game analysis of central government, local governments, and land-lost farmers," Sustainability, vol. 9, no. 4, pp. 648-662, 2017.

[62] Y. Sheng, W. Zhou, and B. Zhu, "The coordination of stakeholder interests in environmental regulation: lessons from China's environmental regulation policies from the perspective of the evolutionary game theory," Journal of Cleaner Production, vol. 249, 2020. 